УДК $621.396 .67(045)$

\title{
МЕТРОЛОГИЧЕСКИЕ ХАРАКТЕРИСТИКИ АНТЕННОЙ СИСТЕМЫ ДЛЯ ИЗМЕРЕНИЯ ПАРАМЕТРОВ ЭЛЕКТРОМАГНИТНОГО ПОЛЯ
}

\author{
ИЛЬНИЦКИЙ Л. Я., ЩЕРБИНА О. А., МИХАЛЬЧУК И. И. \\ Национальный авиационный университет, \\ Украина, Киев, 03058, пр-т Космонавта Комарова, 1
}

\begin{abstract}
Аннотация. Представлен анализ погрешностей измерения параметров электромагнитного поля пятиэлементной антенной системой. Выведены аналитические соотношения для основных погрешностей. Рассчитаны максимальные значения погрешностей измерения
\end{abstract}

Ключевые слова: измерительная антенна; радиомониторинг; погрешность измерения; напряженность электромагнитного поля

\section{ВСТУПЛЕНИЕ}

Для радиомониторинга электромагнитной обстановки, радиоконтроля электромагнитных излучений, исследования особенностей распространения электромагнитных волн и других подобных применений разработана универсальная измерительная антенная система [1].

Основные преимущества антенной системы заключаются в том, что она дает возможность по результатам идентификации необходимого излучения без ориентации на источник исследуемого излучения измерить меридиональный $\theta$ и азимутальный $\varphi$ углы прихода электромагнитной волны, вертикальную $E_{\theta}$ и горизонтальную $E_{\varphi}$ составляющие вектора напряженности электрического поля, а также фазовый сдвиг $\psi$ между этими составляющими. Кроме того, поскольку в устройстве обработки сигналов осуществляется настройка каналов обработки на частоту исследуемого излучения, также измеряется частота радиоволны. Если не брать во внимание параметры модуляции, то на выходе антенной системы получены все не-

DOI: $10.20535 / \mathrm{S} 0021347016030055$

() Ильницкий Л. Я., Щербина О. А., Михальчук И. И., 2016 обходимые величины, которые характеризуют какое-либо излучение [2].

Однако в [1] не приведены метрологические характеристики, что существенно ограничивает область применения антенной системы. В настоящей статье для устранения этого недостатка изложены результаты исследования точностных характеристик, которые освещают возможности разработанной антенной системы как устройства для измерения параметров электромагнитного поля.

\section{ПОСТАНОВКА ЗАДАЧИ}

Обобщенная схема антенной системы, представленная на рис. 1 , состоит из пяти вибраторов, интегрированных с блоками обработки сигналов и процессором. Вибраторы 1, 2 располагаются в горизонтальной плоскости и взаимно перпендикулярны. Вибратор 3 размещен в вертикальной плоскости. Фазовые центры вибраторов 1, 2, 3 совмещены и совпадают с началом координат выбранной координатной системы. Вибратор 4 соосный вибратору 3 и удален от него на расстояние $d$. Вибратор 5 со- 